\title{
GPER modulates tone and coronary vascular reactivity in male and female rats
}

\author{
Angelina Rafaela Debortoli', Wender do Nascimento Rouver1, \\ Nathalie Tristão Banhos Delgado', Vinicius Mengal', Erick Roberto Gonçalves Claudio', \\ Laena Pernomian², Lusiane Maria Bendhack², Margareth Ribeiro Moysés ${ }^{1}$ and \\ Roger Lyrio dos Santos ${ }^{1}$
}

1Department of Physiological Sciences, Health Sciences Center, Federal University of Espirito Santo, Vitoria, Brazil 2Department of Physics and Chemistry, Faculty of Pharmaceutical Sciences from Ribeirão Preto, University of São Paulo, São Paulo, Brazil
Correspondence should be addressed to R L dos Santos

Email rogerlyrio@hotmail.com

\begin{abstract}
Compared with age-matched men, premenopausal women are largely protected from coronary artery disease, a difference that is lost after menopause. The effects of oestrogens are mediated by the activation of nuclear receptors (ER $\alpha$ and ER $\beta$ ) and by the $G$ protein-coupled oestrogen receptor (GPER). This study aims to evaluate the potential role of GPER in coronary circulation in female and male rats. The baseline coronary perfusion pressure (CPP) and the concentration-response curve with a GPER agonist (G-1) were evaluated in isolated hearts before and after the blockade of GPER. GPER, superoxide dismutase (SOD-2), catalase and gp91phox protein expression were assessed by Western blotting. Superoxide production was evaluated 'in situ' via dihydroethidium fluorescence (DHE). GPER blockade significantly increased the CPP in both groups, demonstrating the modulation of coronary tone by GPER. G-1 causes relaxation of the coronary bed in a concentration-dependent manner and was significantly higher in female rats. No differences were detected in GPER, SOD-2 and catalase protein expression. However, gp91phox expression and DHE fluorescence were higher in male rats, indicating elevated superoxide production. Therefore, GPER plays an important role in modulating coronary tone and reactivity in female and male rats. The observed differences in vascular reactivity may be related to the higher superoxide production in male rats. These findings help to elucidate the role of GPER-modulating coronary circulation, providing new information to develop a potential therapeutic target for the treatment of coronary heart disease.
\end{abstract}

Journal of Molecular Endocrinology (2017) 59, 171-180

\section{Introduction}

It is well known that men are more susceptible to the risk of developing cardiovascular diseases (CVDs) compared with premenopausal women. Despite this sex difference, CVDs are also the leading cause of death among

$\begin{aligned} & \text { Key Words } \\ \text { - } & \text { coronary arteries } \\ \text { - } & \text { GPER } \\ \text { - } & \text { G-1 } \\ \text { - } & \text { sex differences } \\ \text { - } & \text { vasodilation }\end{aligned}$

post-menopausal women (Mosca et al. 2004, Heron 2013), possibly because of changes in hormone levels (Reslan \& Khalil 2012), specifically the decrease in plasma oestrogen levels (Mendelsohn \& Karas 2007). Thus, previous studies 
have suggested that oestrogen (primarily $17 \beta$-oestradiol, E2) plays a protective role in the cardiovascular system in women (Kurt \& Buyukafsar 2013, Santos et al. 2014).

E2 can have genomic (or nuclear) and non-genomic (or extra-nuclear) effects via activation of its classic receptors, the $\alpha$ and $\beta$ oestrogen receptors (ER $\alpha$ and ER $\beta$ ), and through binding to a membrane receptor known as the G protein-coupled oestrogen receptor (GPER), which is also referred to as GPR30 (Filardo et al. 2000, Revankar et al. 2005). Currently, to explore the various functions of GPER across multiple systems, including the cardiovascular system, a selective agonist for this receptor (G-1) has been extensively used (Bologa et al. 2006, Nilsson et al. 2011).

The vascular effects of G-1 have been evaluated in various arteries. This agonist has been found to function as a dilator in internal mammary arteries in humans (Haas et al. 2007, 2009), the thoracic aorta in mRen2.Lewis rats (Lindsey et al. 2009), the aorta (Jang et al. 2013) and the mesenteric artery in rats (Lindsey et al. 2011a), the coronary artery in pig (Meyer et al. 2010), spontaneously hypertensive rats (De Francesco et al. 2013) and the carotid artery in male and female Sprague-Dawley rats, and these effects may be related to significantly decreased NADPHstimulated superoxide production and the direct action of G-1 as a superoxide scavenger independent of GPER (Broughton et al. 2010). In fact, others studies have shown that GPER may mediate effects by changing the oxidative (Lindsey et al. 2011b, Liu et al. 2016, Yao \& Abdel-Rahman 2016) or antioxidative pathways (Kurt et al. 2015, 2016, Li et al. 2015). However, the relationship between GPER and these pathways has been not well described.

In contrast, Kurt and Buyukafsar (2013) showed that G-1 administered in increasing concentrations triggers vasoconstriction in isolated and perfused kidneys in rats, suggesting that it exhibits diverse functions that may vary depending on the artery bed under investigation.

However, whether GPER modulates coronary vascular tone and the potential effects of GPER activation on coronary circulation in the presence of its agonist in male and female rats remains unclear. Therefore, the present study aimed to evaluate potential sex differences in the modulation of basal tone by GPER and the effects exerted by G-1 on the reactivity of the coronary vascular bed.

\section{Materials and methods}

\section{Experimental animals}

The present study used 10-week-old adult Wistar rats (Rattus norvegicus albinus) of both sexes reared at the animal facility of the Health Sciences Center at the Federal University of Espírito Santo. All procedures were approved by the Ethics Committee on the Use of Experimental Animals of UFES under protocol No. 048/2013. The animals were maintained in group cages with free access to water and food (Purina Labina, São Paulo, Brazil), under controlled conditions of temperature $\left(22-24^{\circ} \mathrm{C}\right)$ and humidity (40-60\%), with a 12/12-h light-darkness cycle.

\section{Experiments in isolated hearts}

Animals were anaesthetised with sodium pentobarbital administered intraperitoneally (i.p.) at $50 \mathrm{mg} / \mathrm{kg}$, and killed via decapitation. After opening of the thoracic cavity, the heart was exposed, freed from surrounding tissues, and rapidly transferred to an apparatus for perfusion of the isolated heart with aortic cannulation. The coronary vascular bed was examined using the modified Langendorff method (Hugo Sachs Electronics, March-Hugstetten, Germany) as described previously (Santos et al. 2004). Briefly, isolated hearts were perfused with modified Krebs solution $(120 \mathrm{mM} \mathrm{NaCl}$, $1.25 \mathrm{mM} \mathrm{CaCl}_{2} \cdot 2 \mathrm{H}_{2} \mathrm{O}, 5.4 \mathrm{mM} \mathrm{KCl}, 2.5 \mathrm{mM} \mathrm{MgSO}_{4} \cdot 7 \mathrm{H}_{2} \mathrm{O}$, $2.0 \mathrm{mM} \mathrm{NaH}_{2} \mathrm{PO}_{4} \cdot \mathrm{H}_{2} \mathrm{O}, 27.0 \mathrm{mM} \mathrm{NaHCO}, 1.2 \mathrm{mM} \mathrm{Na}_{2} \mathrm{SO}_{4}$, $0.03 \mathrm{mM}$ EDTA, and $11.0 \mathrm{mM}$ glucose), heated continuously at $37^{\circ} \mathrm{C}$ in a water bath, and gassed with a carbogenic mixture of $95 \% \mathrm{O}_{2}$ and $5 \% \mathrm{CO}_{2}$ in a saturation chamber to maintain a stable $\mathrm{pH}$ of 7.4. A constant coronary flow of $10 \mathrm{~mL} / \mathrm{min}$ was maintained using a roller pump (Hugo Sachs), and the changes in coronary perfusion pressure (CPP) were directly associated with changes in vascular resistance.

The baseline CPP was measured using a pressure transducer (ADInstruments MLT0380/A Reusable BP Transducer, ADInstruments, Australia) connected to a digital data acquisition system (Power Lab System, AD Instruments, Bella Vista, New South Wales, Australia). The transducer was fixed near the aortic perfusion cannula, through which the coronary bed was perfused. LabChart software version 7.3.1 (ADInstruments) was employed for reading the recordings obtained with the data acquisition system. A latex balloon located at the end of a steel cannula was inserted into the left ventricle and connected to the pressure transducer to measure the isovolumetric cardiac force. The balloon was inflated with the aid of a glass syringe to maintain a preload of $10 \mathrm{mmHg}$. After a 40-min stabilisation period, the baseline CPP was measured. To evaluate the vascular response to G-1, a dose-response curve (600-10,000 nM) for G-1 (Azano Pharmaceuticals, NM, USA) was obtained after in bolus infusion. The relaxing response was expressed as the percentage of relaxation and calculated by the following equation:

Published by Bioscientifica Ltd 


$$
\Delta \%\left(\frac{\mathrm{CPP}_{\text {after inf usion }} \times 100}{\mathrm{CPP}_{\text {before inf usion }}}\right)-100
$$

In addition, to evaluate GPER modulation of the basal tone of the coronary bed, a selective GPER antagonist (G36 at $1 \mu \mathrm{M}$; Azano Pharmaceuticals, NM, USA) was added to the modified Krebs solution, which was perfused for at least $20 \mathrm{~min}$, and the CPP was measured again. Both G-1 and G36 were diluted in dimethylsulfoxide $(<0.01 \%)$. The dimethylsulfoxide concentration used as solvent in this study had no effect when used by in bolus administration (data not shown).

\section{Dissection of the coronary arteries}

The coronary arteries were dissected as described previously (Claudio et al. 2013). Briefly, animals were anaesthetised with sodium pentobarbital at $50 \mathrm{mg} / \mathrm{kg}$ i.p. and killed via decapitation. The thoracic cavity was opened, and the heart was removed and maintained in a modified Krebs solution $\left(120 \mathrm{mM} \mathrm{NaCl}, 1.25 \mathrm{mM} \mathrm{CaCl}{ }_{2} .2 \mathrm{H}_{2} \mathrm{O}\right.$, $5.4 \mathrm{mM} \mathrm{KCl}, 2.5 \mathrm{mM} \mathrm{MgSO}{ }_{4} .7 \mathrm{H}_{2} \mathrm{O}, 2.0 \mathrm{mM} \mathrm{NaH} \mathrm{PO}_{4}$. $\mathrm{H}_{2} \mathrm{O}, 27.0 \mathrm{mM} \mathrm{NaHCO}, 1.2 \mathrm{mM} \mathrm{Na}_{2} \mathrm{SO}_{4}, 0.03 \mathrm{mM}$ EDTA, and $11.0 \mathrm{mM}$ glucose). The anterior descending branch of the left coronary artery and the septal branch were isolated with the aid of a dissecting microscope (M900, F. Vasconcelos, São Paulo, Brazil) and then freed from surrounding muscle tissue and frozen at $-80^{\circ} \mathrm{C}$ until use.

\section{Western blotting}

The coronary arteries were homogenised in lysis buffer (150 mM NaCl, 50 mM Tris-HCl, $5 \mathrm{mM}$ EDTA.2Na, and $1 \mathrm{mM} \mathrm{MgCl} 2$ ), and a protease inhibitor (Sigma Fast, Sigma) was added. The protein concentration was measured using the Lowry method (Lowry et al. 1951), and bovine serum albumin was employed as a standard. Equal amounts of protein $(50 \mu \mathrm{g})$ were separated via 10\% SDS-PAGE. The proteins were subsequently transferred to polyvinylidene difluoride (PVDF) membranes and incubated with a rabbit monoclonal anti-GPER antibody (1:500; Santa Cruz Biotechnology, cat. Sc-48524-R; lot \#C1414), a rabbit polyclonal anti-SOD-2 antibody (1:1000; Sigma, cat. SAB2102261, lot \#QC25874), a rabbit polyclonal anti-gp9phox antibody (1:1000; BD Biosciences, cat. 611414, lot \#2146906, NJ, USA), a mouse monoclonal anti-catalase antibody (1:2000; Sigma, cat. C0979, lot. \#082M4837) and a mouse monoclonal anti- $\beta$-actin antibody (1:5000; Sigma, cat. A5442, lot \#061M4808). After washing, the membranes were incubated with alkaline phosphatase-conjugated anti-rabbit (1:7000, Santa Cruz Biotechnology) or anti-mouse (1:3000, Abcam) secondary antibody. Bands were visualised using a 5-bromo-4-chloro-3-indolyl-phosphate/nitro blue tetrazolium (BCIP/NBT) system (Invitrogen Corporation) and quantified with ImageJ software (National Institute of Health, NIH). Protein expression was calculated based on the ratio of the specific density of each protein band vs the corresponding density of $\beta$-actin.

\section{Dihydroethidium (DHE) fluorescence}

The coronary arteries were isolated, cleaned, freed from surrounding tissues and immediately frozen in cryoprotection liquid (Tissue Tek - OCT). The blocks containing the coronary arteries were stored at $-70^{\circ} \mathrm{C}$ until the preparation of sections using a cryostat $(10-\mathrm{mm}$ thick sections prepared at $-25^{\circ} \mathrm{C}$ in the dark). The slides were stored at $-20^{\circ} \mathrm{C}$ until use.

For analysis of DHE fluorescence, the sections were washed with complete modified Hanks' solution $(1.6 \mathrm{mM}$ $\mathrm{CaCl}_{2}, 1.0 \mathrm{mM} \mathrm{MgCl}_{2}, 120.0 \mathrm{mM} \mathrm{NaCl}, 5.0 \mathrm{mM} \mathrm{KCl}$, $0.5 \mathrm{mM} \mathrm{NaH}_{2} \mathrm{PO}_{4}, 10.0 \mathrm{mM}$ glucose and $10.0 \mathrm{mM}$ HEPES at $\mathrm{pH}$ 7.4) and subsequently incubated with DHE (which is selective for the superoxide anion, $10 \mu \mathrm{mol} / \mathrm{L}$ ) for $30 \mathrm{~min}$ at room temperature. After the incubation period, the slides were washed, coverslipped with $24 \times 50 \mathrm{~mm}$ coverslips (Knittel Glaser) and examined on a confocal microscope (Leica TSC SP2 or SP5) with an oil-immersion objective at a magnification of $63 \times$. Leica Application Suite-Advanced Fluorescence Lite 2.3.0 (LAS-AF Lite, Leica Microsystems, 1997-2010) analysis software was used to capture images of the sections in $x y z$ mode, with sequence analysis, bidirectional -29.49 analysis at $200 \mathrm{~Hz}$ in the $1024 \times 1024$ format, a zoom of 1 and a magnification of $63 \times$ in TCS SP2 or SP5 acquisition mode. Photomicrographs from 3 to 5 animals per group were compared in terms of the same area of vascular smooth muscle (VSM) (rectangles of $1.00 \times 0.60$ from 5 different regions of VSM) and analysed with ImageJ software (1.46r, NIH).

\section{Statistical analysis}

Data are expressed as the mean \pm s.E.M. To identify possible outlier data, a two-sided Grubbs' test was used to identify whether at least one outlier was present in each data set. When the Grubbs' test identified one outlier, we used an adapted ROUT method to detect any outliers from the column data and removed them according to a $Q$ setting of $1 \%$ (alpha $=0.01)$. For each data set, the D'Agostino-Pearson

Published by Bioscientifica Ltd 
omnibus normality tests were also performed. Paired or unpaired Student's $t$ test was used to analyse coronary protein expression and dihydroethidium fluorescence. CPP data and vascular reactivity to G-1 were analysed by two-way analysis of variance (ANOVA), followed by the Bonferroni post hoc test. Each $P$ value is adjusted to account for multiple comparisons. Statistical significance was set at $P<0.05$.

\section{Results}

\section{Basal CPP}

Basal CPP levels (Fig. 1) were significantly higher in female rats $(109 \pm 3 \mathrm{mmHg})$ compared with male rats $(69 \pm 3 \mathrm{mmHg}, P<0.0001)$. Moreover, CPP levels increased significantly in both female $(133 \pm 10 \mathrm{mmHg}$, $P=0.0195)$ and male rats $(83 \pm 7 \mathrm{mmHg}, P=0.044)$ after the addition of the selective GPER antagonist (G36) to

\section{A}

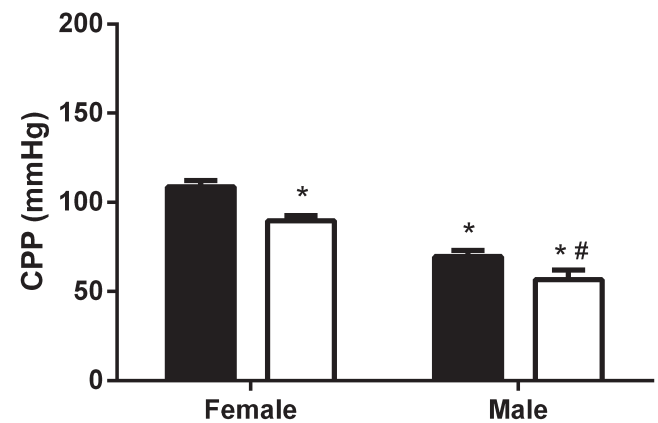

B

After G36

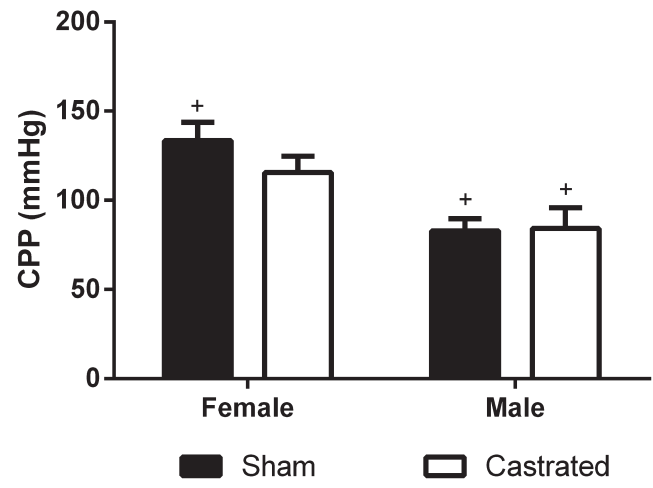

Figure 1

Basal coronary perfusion pressure (CPP) in isolated hearts before $(A)$ and after (B) the antagonism of GPER with G36 from sham and castrated female and male rats. Data are expressed as the mean \pm S.E.M. ( $n=7$ per group). ${ }^{*} P<0.05$ vs baseline from sham female rats; ${ }^{P} P<0.05$ vs baseline from castrated female rats; $+P<0.05$ vs to the same group under control conditions (before G36, shown in panel A). For the analysis, two-way ANOVA was used, followed by the Bonferroni post hoc test. the modified Krebs solution, demonstrating for the first time important contribution of GPER to the modulation of coronary vascular tone. To confirm the participation of sex hormones in the CPP, the animals were castrated. Castration caused a significant reduction in the baseline CPP only in the female group $(108.8 \pm 3.4-$ $89.73 \pm 2.7 \mathrm{mmHg}, \quad P=0.0156)$. The use of G36 in castrated animals increased the CPP only in the male group $(56.79 \pm 5.4-84.19 \pm 11.8 \mathrm{mmHg}, P=0.0293$; Fig. 1$)$.

\section{Vascular reactivity of the isolated coronary bed}

To evaluate the vascular reactivity of the coronary bed in response to the GPER receptor agonist, a dose-response curve for G-1 was constructed (Fig. 2). We observed a progressive, dose-dependent vasodilation of the coronary bed in female rats in response to $\mathrm{G}-1(600 \mathrm{nM}$ vs $3000 \mathrm{nM}$, $P=0.0340 ; 1000 \mathrm{nM}$ vs $6000 \mathrm{nM}, P<0.0001 ; 3000 \mathrm{nM}$ vs $6000 \mathrm{nM}, P=0.0079$ and $6000 \mathrm{nMvs} 10,000 \mathrm{nM}, P=0.0026$ ). However, in the male group this response was significant only at the highest dose $(600 \mathrm{nM}$ vs $10,000 \mathrm{nM}, P=0.0029$ and $1000 \mathrm{nM}$ vs $10,000 \mathrm{nM}, P=0.0132$ ). Furthermore, the relaxing response was significantly higher in female rats $(P<0.0001)$. Nevertheless, in the presence of the inhibitor G36, G-1-induced dilation was abolished in male rats $(P<0.0001)$ and reverted to vasoconstriction in female rats $(P<0.0001)$.

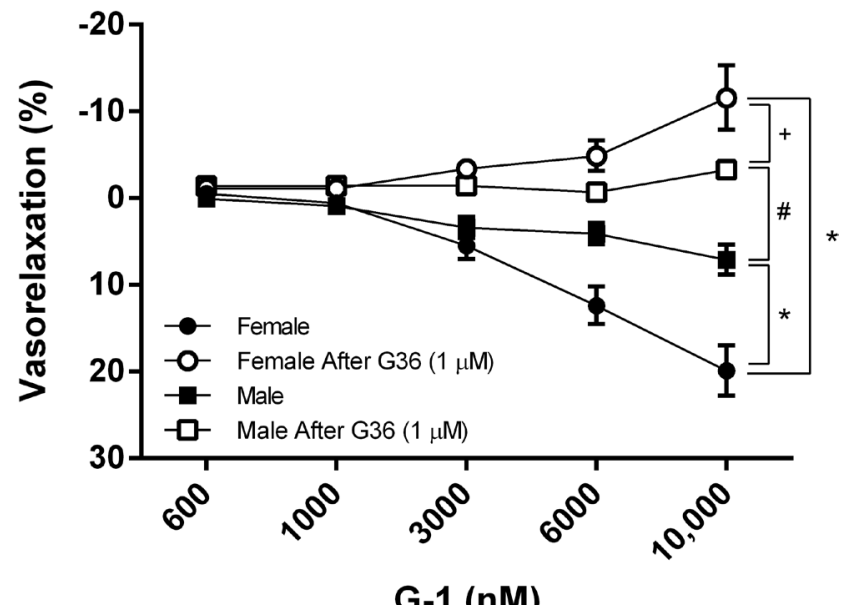

Figure 2

Dose-response curve for the agonist G-1 $(600-10,000 \mathrm{nM})$ in female rats before ( $n=8$, filled circles) and after ( $n=7$, open circles) blockade with G36 and in male rats before ( $n=9$, filled squares) and after ( $n=7$, open squares) the same treatment. Note that the downward deflections (positive values) represent vasorelaxation, while the upward deflections (negative values) represent vasoconstriction. Data are expressed as the mean+s.E.M. $* P<0.05$ vs the female group before $\mathrm{G} 36, \# P<0.05$ vs the male group before $\mathrm{G} 36$ and $+P<0.05$ vs the female group after $\mathrm{G} 36$. For the analysis, two-way ANOVA was used, followed by the Bonferroni post hoc test.

Published by Bioscientifica Ltd. 
GPER - 38 kDa $\beta$-Actin - 42 kDa

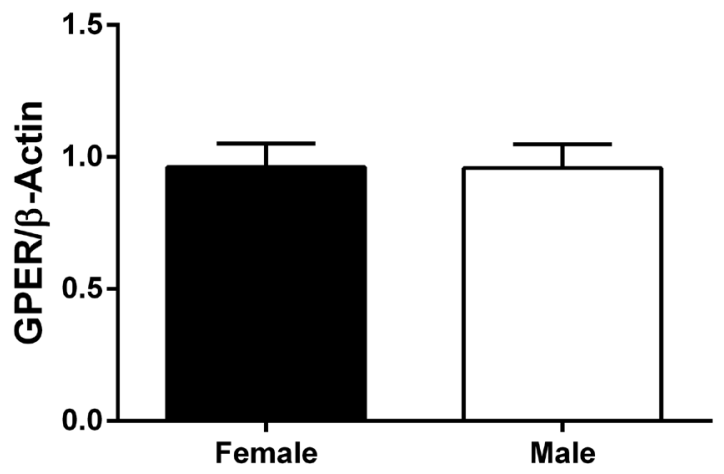

Figure 3

Coronary protein expression of GPER from female $(n=8)$ and male rats $(n=7)$. Data are expressed as the mean \pm S.E.M. ${ }^{*} P<0.05$ vs female rats. For the analysis, an unpaired Student's $t$ test was used.

\section{Protein expression}

Protein expression in coronary arteries is presented in Figs 3 and 4. GPER (Fig. 3), SOD-2 and catalase expression did not differ significantly between male and female rats (Fig. 4A and B). However, the expression of the membrane-bound subunit of Nox2 (i.e., gp91phox) significantly increased in the coronary arteries of male rats (Fig. $4 \mathrm{C} ; P<0.05$ ).

\section{Measurement of superoxide anion $\left(\mathrm{O}_{2}^{-}\right)$by DHE fluorescence}

The analysis of DHE fluorescence in coronary arteries is summarised in Figs 5 and 6. The results indicate that $\mathrm{O}_{2}^{-}$fluorescence levels were higher in male rats (Fig. 5C and D) compared with female rats (Fig. 5A and B). After stimulation with G-1, $\mathrm{O}_{2}^{-}$fluorescence levels increased in male rats (Fig. 6C), while no difference was observed in the female group (Fig. 6G).

\section{Discussion}

The present study aimed to evaluate the role of GPER in modulating basal tone and coronary vascular reactivity in male and female rats. The main findings of this study are as follows: (i) GPER plays an important role in the modulation of coronary basal tone in male and female rats, and (ii) G-1 promotes vasodilation of the coronary bed in male and female rats; this response is more pronounced in female rats, despite the lack of a difference in GPER expression.

Another important observation was the difference in basal CPP levels between the sexes, with significantly higher basal CPP levels being observed in female rats. This result was similar to those of previous studies from our laboratory performed using normotensive animals (Moyses et al. 2001, Santos et al. 2004, 2016) and spontaneously hypertensive rats (Santos et al. 2010). In addition, this difference was maintained even when a selective GPER antagonist was added to the modified Krebs solution.

The mechanisms responsible for the increased CPP levels observed in female rats compared with male rats of the same age have not been fully elucidated. However, Figueroa-Valverde and coworkers (Figueroa-Valverde et al. 2011) demonstrated that oestradiol infusion significantly increased the perfusion pressure and coronary resistance of isolated hearts in rats due to an increase in calcium levels via activation of L-type calcium channels through nongenomic molecular mechanisms. In fact, our results show that after castration, the CPP was significantly reduced in the female group. Consistent with the involvement of oestradiol in modulating the CPP, Moyses and coworkers
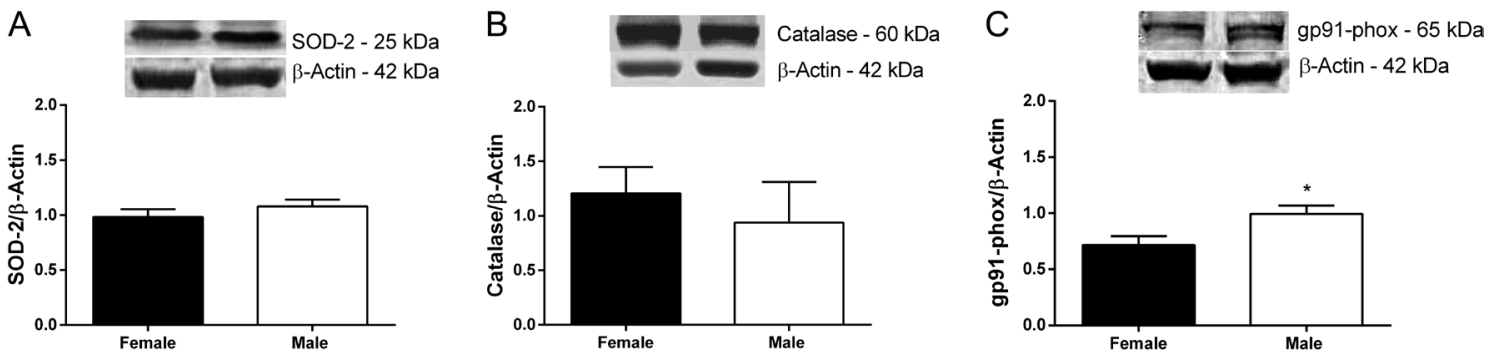

Figure 4

Coronary protein expression of the antioxidant enzymes SOD-2 (A) and catalase (B) and the gp91phox subunit of the NADPH oxidase enzyme complex (C) in female $(n=8)$ and male rats $(n=8)$. Data are expressed as the mean \pm S.E.M. $* P<0.05$ vs female rats. For the analysis, an unpaired Student's $t$ test was used. 
Female

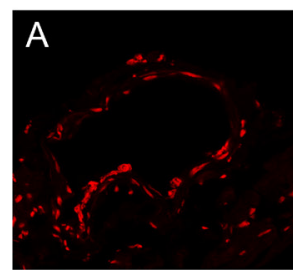

Male

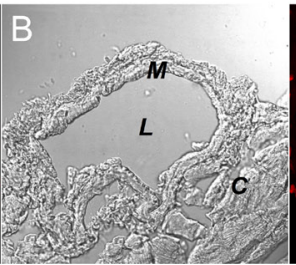

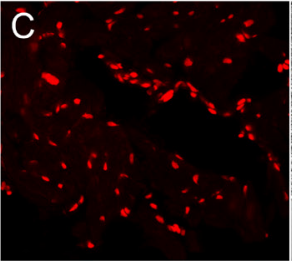

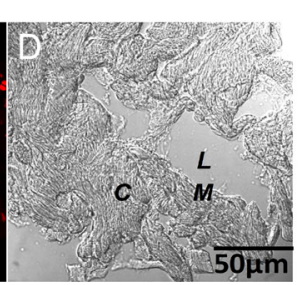

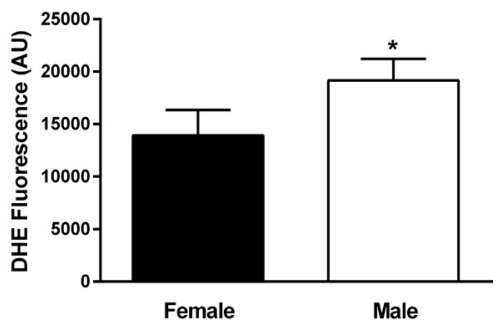

Figure 5

Oxidative stress levels in coronary arteries based on dihydroethidium fluorescence (DHE, red staining) in female $(n=4, \mathrm{~A})$ and male rats $(n=5, \mathrm{C})$. Bar graph shows the measurement of fluorescence intensity emitted by DHE in the medial layer of vascular smooth muscle. Data are expressed as the mean \pm S.E.M. ${ }^{*} P<0.05$ vs female rats. Photomicrographs are related to dichroic phase contrast, identifying the lumen (L), medial layer of vascular smooth muscle (M) and cardiomyocytes (C) from females (B) and males (D). Bar corresponds to $50 \mu m$. For the analysis, an unpaired Student's $t$ test was used.

(Moyses et al. 2001) showed that oestrogen replacement in gonadectomized rats restores the baseline CPP in females and increases the CPP in males to become similar to those found in naive female animals. Indeed, a recent study from our group also showed that gonadectomy reduces the baseline CPP in females and has no effect on the baseline CPP of hearts from male rats (Santos et al. 2016). Notably, even after gonadectomy, these differences in the CPP continued to exist between females and males, perhaps because the benefits of oestrogens on the coronary arteries were not completely lost after gonadectomy. Therefore, we suggest that the higher basal tone found in female rats is due to oestrogen. Higher CPP could allow greater vasodilation, thus exerting cardioprotective effects when the supply of oxygen and nutrients are reduced (Santos et al. 2016).

After perfusion with G36, the CPP significantly increased in sham animals of both sexes. Although other studies have used Langendorff's technique to assess the role of GPER in cardiac parameters (Bopassa et al. 2010, Kabir et al. 2015), to our knowledge, our study is the first to show that GPER plays an important role in the local modulation of the vascular tone of the coronary bed. GPER appears to exert a negative modulatory effect on the elevation of the CPP induced by oestrogen. In fact, after the use of G36 in sham females, the CPP increased significantly, indicating that G36 removes this negative modulatory effect. In castrated females, on the other hand, the effect of CPP elevation induced by oestrogen would not occur, indicating that the use of G36 would not have the same effect as that observed in the sham group, which would explain why we did not observe differences in CPP in castrated females after blockade with G36.

To our knowledge, this study is the first to demonstrate the vasodilatory effect of G-1 in the coronary vascular bed, since the vascular action of this compound has
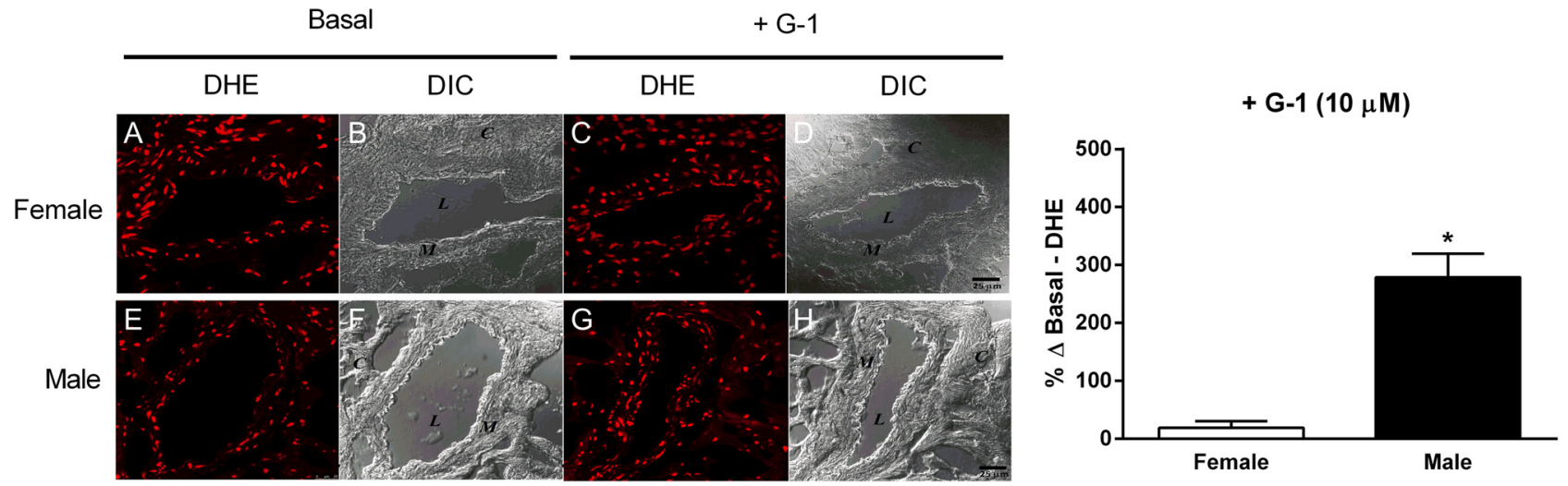

Figure 6

Oxidative stress levels in coronary arteries based on dihydroethidium fluorescence (DHE, red staining) after G-1 stimulation in female ( $n=4$, A, B, C and D) and male rats $(n=5, E, F, G$ and H). Bar graph represents the variation (percentage) from the baseline of fluorescence intensity emitted by DHE ( $\% \Delta$ basal) in the media layer of vascular smooth muscle. Data are expressed as the mean \pm S.E.M. ${ }^{*} P<0.05$ vs female rats. Photomicrographs are related to dichroic phase contrast, identifying the lumen (L), medial layer of vascular smooth muscle (M) and cardiomyocytes (C) from females (B and D) and males $(\mathrm{F}$ and $\mathrm{H}$ ). Bar corresponds to $25 \mu \mathrm{m}$. For the analysis, a unpaired Student's $t$ test was used.

http://jme.endocrinology-journals.org DOI: 10.1530/JME-16-0117
(C) 2017 Society for Endocrinology Printed in Great Britain
Published by Bioscientifica Ltd 
been evaluated previously only in isolated vessels, as shown by Lindsey and coworkers (Lindsey et al. 2011a). In our study, the acute administration of G-1 promoted vasodilation in the coronary vascular beds of isolated hearts from male and female rats. Our previous studies have already demonstrated that E2 is able to induce a relaxing response in the coronary vessel (Santos et al. 2004, 2010, 2012, 2016). However, such actions could not be directly attributed to GPER, since oestradiol also acts on intracellular receptors (ER $\alpha$ and $E R \beta)$. Indeed, G-1 has been shown to induce endothelium-dependent dilation that is not affected by the concomitant blockade of ER $\alpha$ and ER $\beta$ (Meyer et al. 2010).

Our study also revealed sex differences in G-1-induced relaxation. Lindsey and coworkers (Lindsey et al. 2013) reported a similar difference using G-1 as a vasodilator agonist; however, this study was performed in mesenteric arteries. In resistance arteries obtained from subcutaneous tissues of humans, G-1-induced relaxation was found to be significantly greater among post-menopausal women compared with men from the same age group (Arefin et al. 2014). In contrast, in carotid arteries (Broughton et al. 2010) and cerebral arterioles of Sprague-Dawley rats (Murata et al. 2013), no differences in G-1-induced relaxation were observed between the sexes.

To evaluate whether the increased vasodilator response to G-1 found in female rats was associated with higher GPER protein expression in coronary arteries, we measured the protein expression of this receptor; however, no significant differences were observed between the groups. Other studies have shown similar results, such as no differences in GPER expression in the brains (Matsuda et al. 2008) and cardiomyocytes (Deschamps \& Murphy 2009) of male and female Sprague-Dawley rats. In contrast, Lindsey and coworkers (Lindsey et al. 2013) reported increased GPER expression in mesenteric arteries of female mRen2.Lewis rats.

Considering that no differences in GPER expression were found in coronary arteries in male and female rats, we evaluated whether the weaker dilation observed in male rats was due to a greater basal production of reactive oxygen species (ROS) compared with female rats according to our DHE results. Indeed, $\mathrm{O}_{2}^{-}$generation was higher in males even after stimulation with G-1. ROS production can impair the vascular response by interacting with the main factors responsible for vascular relaxation (Zou \& Ulrich 1996, Liu et al. 2002, Fösterman 2010).

Accordingly, we evaluated the expression of antioxidant enzymes such as SOD-2 and catalase.
Furthermore, we analysed the gp91phox isoform of the NADPH oxidase enzyme complex. Our results indicate that SOD-2 and catalase protein expression was similar in both sexes; however, gp91phox expression was higher in male rats. These results support our hypothesis that higher oxidative stress in males may have contributed to the weaker response to G-1 in this group compared with females. In male animals, aside from the lower oestrogen levels, testosterone activates NADPH oxidase via the renin-angiotensin system (Fischer et al. 2002, Costa et al. 2015), contributing to high $\mathrm{O}_{2}^{-}$generation, one of the most important ROS (Chignalia et al. 2012). Superoxide, in turn, quickly reacts with NO and reduces its bioavailability, which may explain the lower relaxing response in the male group. In addition, the product of the reaction between $\mathrm{NO}$ and $\mathrm{O}_{2}^{-}$i.e., peroxynitrite $\left(\mathrm{ONOO}^{-}\right)$, is able to reduce the synthesis of prostacyclin $\left(\mathrm{PGI}_{2}\right)$, even at lower concentrations $\left(10^{-8} \mathrm{M}\right)$ (Zou \& Ulrich 1996). Furthermore, $\mathrm{ONOO}^{-}$also impairs EDHF-mediated vasodilation reducing $\mathrm{K}^{+}$channel activity (Liu et al. 2002). The effect of GPER on oxidative stress is not fully elucidated. Indeed, Yao and Abdel-Rahman (2016) showed that acute GPER blockade with G15 attenuated ethanolevoked increases in myocardial ROS. On the other hand, Broughton and coworkers (Broughton et al. 2010), also using an acute analysis protocol, examined whether G-1 directly scavenges superoxide using a cell-free enzyme assay. They found that in the presence of the GPER agonist G-1, NADPH-stimulated superoxide in the carotid and intracranial cerebral arteries was $~ 30-40 \%$ lower than levels generated by arteries treated with vehicle. On the other hand, a recent study demonstrated that GPER contributes to increased oxidative stress, thereby regulating NADPH oxidase (Nox), specifically Nox1, even without stimulation by oestrogen (Meyer et al. 2016). When we analysed chronic G-1 treatment, the actions of this GPER agonist seemed to be more homogeneous. In fact, several studies have demonstrated beneficial effects for chronic G-1 administration (Lindsey et al. 2009, Jessup et al. 2010, Li et al. 2012). Lindsey and coworkers (Lindsey et al. 2009) showed that chronic G-1 treatment significantly reduces hypertension in oestrogen-depleted mRen2.Lewis congenic rats. In addition, Jessup and coworkers (Jessup et al. 2010) found that chronic GPER activation improved myocardial relaxation in hypertensive female mRen2.Lewis rats and reduced cardiac myocyte hypertrophy and wall thickness in rats fed a high-salt diet. Nevertheless, Li and coworkers (Li et al. 2012) demonstrated that following chronic administration of http://jme.endocrinology-journals.org DOI: 10.1530/JME-16-0117
() 2017 Society for Endocrinology Printed in Great Britain
Published by Bioscientifica Ltd 
G-1 (200 $\mu$ g/kg i.p., 2 times per day for 8 weeks), AChinduced relaxation in the aortic segments from the diabetic OVX rats was significantly enhanced. Although chronic G-1 treatment appears not to be controversial, the exact mechanics related to the chronic actions of this GPER agonist have not yet been fully elucidated.

To confirm that the vasodilator response in the coronary bed was mediated by GPER, this receptor was blocked with G36. Indeed, this antagonist completely abolished G-1-induced relaxation in both sexes confirming the involvement of GPER. Nevertheless, GPER antagonism surprisingly converted the vasodilator response to a vasoconstrictor response in female rats. Kurt and Buyukafsar (2013) also demonstrated that G-1 is able to induce vasoconstriction. However, these authors observed this response before the antagonism of GPER. Therefore, the mechanisms involved in the vasoconstrictor response in female rats following the antagonism of GPER remain unclear, and further studies are necessary.

Recent studies using G15, another GPER antagonist that is less selective than G36 (Dennis et al. 2011), have indicated that pharmacological blockade of GPER attenuates the vascular relaxation induced by E2 and G-1 in aortic rings of female mRen2.Lewis rats (Lindsey et al. 2011a) and attenuates the relaxation of the coronary arteries in pigs (Yu et al. 2011).

In conclusion, our results indicate that GPER modulates basal tone and coronary vascular reactivity in male and female rats and that this modulation is more pronounced in female rats. However, although GPER protein expression in coronary arteries was similar between the sexes, the decreased response observed in male rats appears to be associated with higher oxidative stress in this group, likely due to higher expression of the pro-oxidant enzyme gp91phox. Notably, our findings may help elucidate the role of G-1 in coronary arteries, thereby contributing to the following: (i) our understanding of the actions of G-1 on the coronary arteries and (ii) the elucidation of the sex differences in the actions of this GPER agonist. Characterising these mechanisms may lead to a better understanding of GPER actions in the cardiovascular system and perhaps to the development of improved therapeutic strategies.

\section{Declaration of interest}

The authors declare that there is no conflict of interest that could be perceived as prejudicing the impartiality of the research reported.
Funding

This work was supported by FAPES (67665977) and CNPq (55262312011-3).

\section{Author contribution statement}

A R D conceived and designed the experiments, performed the experiments, analysed the data, contributed reagents/materials/analysis tools and wrote the paper. W N R and N T B D performed the experiments, analysed the data, contributed reagents/materials/analysis tools and wrote the paper. V M performed the experiments and contributed reagents/ materials/analysis tools. E R G C performed the experiments, analysed the data, contributed reagents/materials/analysis tools, wrote the paper and critically read the manuscript. L P performed the experiments, contributed reagents/materials/analysis tools, and critically read the manuscript. L M B contributed reagents/materials/analysis tools and critically read the manuscript. M R M conceived and designed the experiments, performed the experiments, analysed the data, contributed reagents/materials/ analysis tools, wrote the paper, and critically read the manuscript. R L S conceived and designed the experiments, performed the experiments, analysed the data, contributed reagents/materials/analysis tools, wrote the paper, and critically read the manuscript.

\section{References}

Arefin S, Simoncini T, Wieland R, Hammarqvist F, Spina S, Goglia L \& Kublickiene K 2014 Vasodilatory effects of the selective GPER agonist G-1 is maximal in arteries of postmenopausal women. Maturitas $\mathbf{7 8}$ 123-130. (doi:10.1016/j.maturitas.2014.04.002)

Bologa CG, Revankar CM, Young SM, Edwards BS, Arterburn JB, Kiselyov AS, Parker MA, Tkachenko SE, Savchuck NP, Sklar LA, et al. 2006 Virtual and biochemical screening converge on a selective agonist for GPR30. Nature Chemical Biology 2 207-212. (doi:10.1038/ nchembio775)

Bopassa JC, Eghbali M, Toro L \& Stefani E 2010 A novel estrogen receptor GPER inhibits mitochondria permeability transition pore opening and protects the heart against ischemia-reperfusion injury. American Journal of Physiology: Heart and Circulatory Physiology 298 H16-H23. (doi:10.1152/ajpheart.00588.2009)

Broughton BR, Miller AA \& Sobey CG 2010 Endothelium-dependent relaxation by $\mathrm{G}$ protein-coupled receptor 30 agonists in rat carotid arteries. American Journal of Physiology 298 H1055-1061. (doi:10.1152/ajpheart.00878.2009)

Chignalia AZ, Schuldt EZ, Camargo LL, Montezano AC, Callera GE, Laurindo FR, Lopes LR, Avellar MC, Carvalho MH, Fortes ZB, et al. 2012 Testosterone induces vascular smooth muscle cell migration by NADPH oxidase and c-Src-dependent pathways. Hypertension 59 1263-1271. (doi:10.1161/HYPERTENSIONAHA.111.180620)

Claudio ERG, Endlich PW, Santos RL, Moyses MR, Bissoli NS, Gouvea SA, Silva JF, Lemos VS \& Abreu GR 2013 Effects of chronic swimming training and oestrogen therapy on coronary vascular reactivity and expression of antioxidant enzymes in ovariectomized rats. PLOS ONE 8 e64806. (doi:10.1371/journal.pone.0064806)

Costa TJ, Ceravolo GS, dos Santos RA, de Oliveira MA, Araújo PX, Giaquinto LR, Tostes RC, Akamine EH, Fortes ZB, Dantas AP, et al. 2015 Association of testosterone with estrogen abolishes the beneficial effects of estrogen treatment by increasing ROS generation in aorta endothelial cells. American Journal Physiology $\mathbf{3 0 8}$ H723-H732. (doi:10.1152/ajpheart.00681.2014)
(C) 2017 Society for Endocrinology Printed in Great Britain
Published by Bioscientifica Ltd 
De Francesco EM, Angelone T, Pasqua T, Pupo M, Cerra MC \& Maggiolini M 2013 GPER mediates cardiotropic effects in spontaneously hypertensive rat hearts. PLOS ONE $\mathbf{8}$ e69322. (doi:10.1371/journal.pone.0069322)

Dennis MK, Field AS, Burai R, Ramesh C, Petrie WK, Bologa CG, Oprea TI, Yamaguchi Y, Hayashi S, Sklar LA, et al. 2011 Identification of a GPER/GPR30 antagonist with improved estrogen receptor counter selectivity. Journal of Steroid Biochemistry and Molecular Biology 127 358-366. (doi:10.1016/j.jsbmb.2011.07.002)

Deschamps AM \& Murphy E 2009 Activation of a novel estrogen receptor, GPER is cardioprotective in male and female rats. American Journal of Physiology 297 H1806-H1813. (doi:10.1152/ ajpheart.00283.2009)

Figueroa-Valverde L, Diaz-Cedillo F, Ramos-Lopez M, Garcia-Cervera E, Quijano K \& Cordoba J 2011 Changes induced by estradiolethylenediamine derivative on perfusion pressure and coronary resistance in isolated rat heart: L-type calcium channel. Biomedical Papers of the Medical Faculty of the University Palacký, Olomouc, Czechoslovakia 155 27-32. (doi:10.5507/bp.2011.018)

Filardo EJ, Quinn JA, Bland KI \& Frackelton AR Jr 2000 Estrogen-induced activation of Erk-1 and Erk-2 requires the G protein-coupled receptor homolog, GPR30, and occurs via trans-activation of the epidermal growth factor receptor through release of HB-EGF. Molecular Endocrinology 14 1649-1660. (doi:10.1210/mend.14.10.0532)

Fischer M, Baessler A \& Schunkert H 2002 Renin-angiotensin system and gender differences in the cardiovascular system. Cardiovascular Research 53 672-677. (doi:10.1016/S0008-6363(01)00479-5)

Förstermann U 2010 Nitric oxide and oxidative stress in vascular disease. Pflugers Archive: European Journal of Physiology 459 923-939. (doi:10.1007/s00424-010-0808-2)

Haas E, Meyer MR, Schurr U, Bhattacharya I, Minotti R, Nguyen HH, Heigl A, Lachat M, Genoni M \& Barton M 2007 Differential effects of 17 beta-estradiol on function and expression of estrogen receptor alpha, estrogen receptor beta, and GPR30 in arteries and veins of patients with atherosclerosis. Hypertension 49 1358-1363. (doi:10.1161/HYPERTENSIONAHA.107.089995)

Haas E, Bhattacharya I, Brailoiu E, Damjanović M, Brailoiu GC, Gao X, Mueller-Guerre L, Marjon NA, Gut A, Minotti R, et al. 2009 Regulatory role of G-protein - coupled estrogen receptor for vascular function and obesity. Circulation Research 104 288-291. (doi:10.1161/ CIRCRESAHA.108.190892)

Heron M 2013 Deaths: leading causes for 2010. National Vital Statistics Reports 62 1-96.

Jang EJ, Seok YM, Arterburn JB, Olatunji LA \& Kim KI 2013 GPER-1 agonist G-1 induces vasorelaxation through activation of epidermal growth factor receptor-dependent signaling pathway. Journal of Pharmacy and Pharmacology 65 1488-1499. (doi:10.1111/jphp.12113)

Jessup JA, Lindsey SH, Wang H, Chappell MC \& Groban L 2010. Attenuation of salt-induced cardiac remodeling and diastolic dysfunction by the GPER agonist G-1 in female mRen2.Lewis rats. PLOS ONE 5 e15433. (doi:10.1371/journal.pone.0015433)

Kabir ME, Singh H, Lu R, Olde B, Leeb-Lundberg LM \& Bopassa JC 2015 $\mathrm{G}$ protein-coupled estrogen receptor 1 mediates acute estrogeninduced cardioprotection via MEK/ERK/GSK-3 $\beta$ pathway after ischemia/reperfusion. PLOS ONE 10 e0135988. (doi:10.1371/journal. pone.0135988)

Kurt AH \& Buyukafsar K 2013 Vasoconstriction induced by G1, a protein-coupled oestrogen receptor 1 agonist, in the isolated perfused rat kidney. European Journal of Pharmacology 702 71-78. (doi:10.1016/j.ejphar.2013.01.020)

Kurt AH, Çelik A \& Kelleci BM 2015 Oxidative/antioxidative enzymemediated antiproliferative and proapoptotic effects of the GPER1 agonist G-1 on lung cancer cells. Oncology Letters 10 3177-3182. (doi:10.3892/ol.2015.3711)

Kurt AH, Bozkus F, Uremis N \& Uremis MM 2016 The protective role of G protein-coupled estrogen receptor 1 (GPER-1) on methotrexate- induced nephrotoxicity in human renal epithelium cells. Renal Failure 16 1-7. (doi:10.3109/0886022X.2016.1155398)

Li ZL, Liu JC, Liu SB, Li XQ, Yi DH \& Zhao MG 2012 Improvement of vascular function by acute and chronic treatment with the GPR30 agonist G1 in experimental diabetes mellitus. PLoS ONE 7 e38787. (doi:10.1371/journal.pone.0038787)

Li WL, Xiang W \& Ping Y 2015 Activation of novel estrogen receptor GPER results in inhibition of cardiocyte apoptosis and cardioprotection. Molecular Medicine Reports 12 2425-2430. (doi:10.3892/mmr.2015.3674)

Lindsey SH, Cohen JA, Brosnihan KB, Gallagher PE \& Chappell MC 2009 Chronic treatment with the G protein-coupled receptor 30 agonist G-1 decreases blood pressure in ovariectomized mRenl. Lewis rats. Endocrinology 150 3753-3758. (doi:10.1210/ en.2008-1664)

Lindsey SH, Carver KA, Prossnitz ER \& Chappell MC 2011a Vasodilation in response to the GPR30 agonist G-1 is not different from estradiol in the mRen2.Lewis female rat. Journal Cardiovascular Pharmacology 57 598-603. (doi:10.1097/FJC.0b013e3182135f1c)

Lindsey SH, Yamaleyeva LM, Brosnihan KB, Gallagher PE \& Chappell MC $2011 b$ Estrogen receptor GPR30 reduces oxidative stress and proteinuria in the salt-sensitive female mRen2.Lewis rat. Hypertension 58 665-71. (doi:10.1161/HYPERTENSIONAHA.111.175174)

Lindsey SH, da Silva AS, Silva MS \& Chapell MC 2013 Reduced vasorelaxation to estradiol and G1 in aged female and adult male rats is associated with GPR30 downregulation. American Journal of Physiology 305 E113-E118. (doi:10.1152/ajpendo.00649.2012)

Liu Y, Terata K, Chai Q, Li H, Kleinman LH \& Gutterman DD 2002 Peroxynitrite inhibits $\mathrm{Ca}^{2+}$-activated $\mathrm{K}^{+}$channel activity in smooth muscle of human coronary arterioles. Circulation Research 91 1070-1076. (doi:10.1161/01.RES.0000046003.14031.98)

Liu L, Kashyap S, Murphy B, Hutson DD, Budish RA, Trimmer EH, Zimmerman MA, Trask AJ, Miller KS \& Chappell MC 2016 GPER activation ameliorates aortic remodeling induced by salt-sensitive hypertension. American Journal of Physiology 310 H953-H961. (doi:10.1152/ajpheart.00631.2015)

Lowry OH, Rosebrough NJ, Farr AL \& Randall RJ 1951 Protein measurement with the Folin phenol reagent. Journal of Biological Chemistry 193 265-275.

Matsuda K, Sakamoto H, Mori H, Kosokawa K, Kawamura A, Itose M, Nishi M, Prossnitz ER \& Kawata M 2008 Expression and intracellular distribution of the G protein-coupled receptor 30 in rat hippocampal formation. Neuroscience Letters 441 94-99. (doi:10.1016/j. neulet.2008.05.108)

Mendelsohn ME \& Karas RH 2007 HRT and the young at heart. New England Journal Medicine 356 2639-2641. (doi:10.1056/ NEJMe078072)

Meyer MR, Baretella O, Prossnitz ER \& Barton M 2010 Dilation of epicardial coronary arteries by the $\mathrm{G}$ protein-coupled estrogen receptor agonists G-1 and ICI 182,780. Pharmacology $\mathbf{8 6}$ 58-64. (doi:10.1159/000315497)

Meyer MR, Fredette NC, Daniel C, Sharma G, Amann K, Arterburn JB, Barton M \& Prossnitz ER 2016 Obligatory role for GPER in cardiovascular aging and disease. Science Signaling 9 ra105. (doi:10.1126/scisignal.aag0240)

Mosca L, Appel LJ, Benjamin EJ, Berra K, Chandra-Strobos N, Fabunmi RP, Grady D, Haan CK, Hayes SN, Judelson DR, et al. 2004 Evidencebased guidelines for cardiovascular disease prevention in women. American Heart Association Scientific Statement 24 e29-e50. (doi:10.1161/01.ATV.0000114834.85476.81)

Moyses MR, Barker JA \& Cabral AM 2001 Sex hormone modulation of serotonin-induced coronary vasodilation in isolated heart. Brazilian Journal of Medical and Biological Research 34 949-958. (doi:10.1590/ S0100-879X2001000700014)

Murata T, Dietrich HH, Xiang C \& Ralph GC Jr 2013 G protein-coupled estrogen receptor agonist improves cerebral microvascular function http://jme.endocrinology-journals.org DOI: 10.1530/JME-16-0117
() 2017 Society for Endocrinology Printed in Great Britain 
after hypoxia/reoxygenation injury in male and female rats. Stroke 44 779-785. (doi:10.1161/STROKEAHA.112.678177)

Nilsson BO, Olde B \& Leeb-Lundber LM 2011 G protein-coupled oestrogen receptor 1 (GPER)/GPR30: a new player in cardiovascular and metabolic oestrogenic signalling. British Journal of Pharmacology 163 1131-1139. (doi:10.1111/j.1476-5381.2011.01235.x)

Reslan OM \& Khalil RA 2012 Vascular effects of estrogenic menopausal hormone therapy. Reviews on Recent Clinical Trials 7 47-70. (doi:10.2174/157488712799363253)

Revankar CM, Cimino DF, Sklar LA, Arterburn JB \& Prossnitz ER 2005 A transmembrane intracellular estrogen receptor mediates rapid cell signaling. Science 307 1625-1630. (doi:10.1126/science.1106943)

Santos RL, Abreu GR, Bissoli NS \& Moysés MR 2004 Endothelial mediators of $17 \beta$-estradiol - induced coronary vasodilation in the isolated rat heart. Brazilian Journal of Medical and Biological Research 37 569-575. (doi:10.1590/S0100-879X2004000400014)

Santos RL, Marin EB, Gonçalves WL, Bissoli NS, Abreu GR \& Moyses MR 2010 Sex differences in the coronary vasodilation induced by 17 $\beta$-estradiol in the isolated perfused heart from spontaneously hypertensive rats. Acta Physiologica 200 203-210. (doi:10.1111/j.1748-1716.2010.02140.x)

Santos RL, Podratz PL, Sena GC, Filho VS, Lopes PF, Gonçalves WL, Alves LM, Samoto VY, Takiya CM, de Castro Miguel E, et al. 2012
Tributyltin impairs the coronary vasodilation induced by $17 \beta$-estradiol in isolated rat heart. Journal of Toxicology and Environmental Health Part A 75 948-959. (doi:10.1080/15287394.2012.695231)

Santos RL, Silva FB, Ribeiro RF Jr \& Stefanon I 2014 Sex hormones in the cardiovascular system. Hormone Molecular Biology and Clinical Investigation 18 89-103. (doi:10.1515/hmbci-2013-0048)

Santos RL, Lima JT, Rouver WN \& Moysés MR 2016 Deficiency of sex hormones does not affect 17- $\beta$-estradiol-induced coronary vasodilation in the isolated rat heart. Brazilian Journal of Medical and Biological Research 49 e5058. (doi:10.1590/1414-431X20165058)

Yao F \& Abdel-Rahman AA 2016 Estrogen receptor ER $\alpha$ plays a major role in ethanol-evoked myocardial oxidative stress and dysfunction in conscious female rats. Alcohol 50 27-35. (doi:10.1016/j. alcohol.2015.11.002)

Yu X, Ma H, Barman SA, Liu AT, Sellers M, Stallone JN, Prossnitz ER, White RE \& Han G 2011 Activation of G protein-coupled estrogen receptor induces endothelium-independent relaxation of coronary artery smooth muscle. American Journal of Physiology: Endocrinology and Metabolism 301 E882-E888. (doi:10.1152/ajpendo.00037.2011)

Zou MH \& Ullrich V 1996 Peroxynitrite formed by simultaneous generation of nitric oxide and superoxide selectively inhibits bovine aortic prostacyclin synthase. FEBS Letters 382 101-104. (doi:10.1016/0014-5793(96)00160-3)

Received in final form 14 June 2017

Accepted 23 June 2017 http://jme.endocrinology-journals.org DOI: 10.1530/JME-16-0117
(C) 2017 Society for Endocrinology Printed in Great Britain
Published by Bioscientifica Ltd 